\title{
Faktor yang Berhubungan dengan Kejadian Dismenore Pada Remaja Putri di MTS Negeri 3 Medan Tahun 2019
}

\author{
Nurul Mouliza \\ Fakultas Farmasi dan Kesehatan, Institut Kesehatan Helvetia, Medan, Indonesia \\ Correspondence email: moulizanurul@gmail.com
}

\begin{abstract}
Abstrak. Dismenore adalah keluhan yang sering dialami pada remaja putri pada saat menstruasi tepatnya diperut bagian bawah. Angka kejadian dismenore di Indonesia sebesar 76\%. Hasil survei awal dari 22 remaja putri terdapat 16 remaja putri mengalami dismenore dan 6 remaja putri lainnya tidak mengalami dismenore. Tujuan Penelitian ini adalah untuk mengetahui faktor yang berhubungan dengan dismenore pada remaja putri di MTs Negeri 3 Medan Tahun 2019. Penelitian ini dilakukan dengan desain penelitian survei analitik dengan pendekatan cross sectional. Populasinya adalah remaja putri di MTs Negeri 3 Medan, yang diambil dengan teknik simple random sampling sebanyak 57 orang. Analisa data menggunakan analisis univariat menggunakan distribusi frekuensi dan analisis bivariat menggunakan uji chi-square. Hasil Penelitian dapat diketahui bahwa dari hasil uji chisquare diperoleh nilai $\mathrm{P}$ Value $=0,045$ yang artinya ada hubungan yang bermakna antara usia menarche dengan dismenore, $\mathrm{P}$ Value $=0,033$ yang artinya ada hubungan yang bermakna antara lama menstruasi dengan dismenore, $\mathrm{P}$ Value $=0,009$ yang artinya ada hubungan yang bermakna antara riwayat keluarga dengan dismenore di MTs Negeri 3 Medan. Berdasarkan hasil penelitian dapat disimpulkan bahwa ada hubungan usia menarche, lama menstruasi dan riwayat keluarga dengan dismenore pada remaja putri di MTs Negeri 3 Medan tahun 2019.
\end{abstract}

Kata Kunci: Dismenore; Lama Menstruasi; Usia Menarche; Riwayat Keluarga

Abstract. Dysmenorrhea is a complaint that is often experienced in adolescent girls during menstruation precisely in the lower abdomen. The incidence of dysmenorrhea in Indonesia is 76\%. The results of an initial survey of 22 young women had 16 young women experiencing dysmenorrhea and 6 other young women not experiencing dysmenorrhea. The purpose of this study was to determine the factor associated with dysmenorrhea in Teenage girls in MTs State 3 Medan in 2019. Methods this research was conducted with an analytic survey research design with a cross-sectional approach. The population is young women in MTS State 3 Medan, taken by simple random sampling technique amounted to 57 people. Data analysis used univariate analysis using frequency distribution and bivariate analysis using chi-square test. Chi-square test results obtained value of P-Value $=.045$ which means there is a significant relationship between the age of menarche with dysmenorrhea, P-Value $=.033$ which means there is a significant relationship between menstrual period with dysmenorrhea, P-Value $=.009$ which it means that there is a significant relationship between family history and dysmenorrhea in MTs State 3 Medan. Based on the results of research can be concluded that there is an age relationship menarche, long menstruation and family history with Dysmenore in young women in MTs Negeri 3 Medan in 2019.

Keywords: Dysmenorrhea; Menstruation Period; Menarche Age; Family History

\section{PENDAHULUAN}

Dismenore atau yang lebih dikenal dengan nyeri haid merupakan keluhan yang sering dialami pada remaja putri tepatmya di perut bagian bawah. Dismenore merupakan penyakit yang sudah cukup lama dikenal, nyeri tersebut dapat disertai mual, muntah, diare, berkeringat dingin dan pusing. Namun belakangan diketahui bahwa nyeri haid tidak hanya dirasakan dibagian perut bagian bawah saja. Beberapa remaja terkadang merasakan dibagian punggung bagian bawah, pinggang, panggul, otot paha hingga betis.

Masa remaja merupakan tahapan antara masa kanak-kanak menuju masa dewasa. Pertumbuhan dan perkembangan pada masa remaja sangat pesat, baik fisik dan psikologis. Organ-organ reproduksi pada masa puber mulai berfungsi. Salah satu ciri masa puber adalah mulai terjadinya menstruasi pada wanita.(Proverawati A,2015)
Kesehatan reproduksi merupakan kesejahteraan fisik, mental, dan sosial yang utuh bukan hanya bebas dari penyakit dan kecacatan dalam segala aspek yang berhubungan dengan sistem reproduksi, fungsi, serta prosesnya. Remaja usia pubertas tidak hanya bertanggung jawab untuk berprestasi akademik, tetapi juga memiliki tanggung jawab untuk menjamin pemeliharaan fungsi reproduksi yang antara lain yaitu menstruasi.(Febriati LD, 2016)

Salah satu tanda seorang wanita memasuki masa pubertas adalah masa menstruasi. Menstruasi merupakan keluarnya lapisan endometrium yang menyertai ovum yang tidak dibuahi dari saluran reproduksi berupa cairan yaitu darah. Salah satu gangguan kesehatan reproduksi yang terkait dengan menstruasi adalah dismenore.(Sari AP, Siregar FA, Rasmaliah, 2017)

Sebagian wanita yang mengalami menstruasi akan timbul nyeri saat menstruasi yang biasanya disebut dismenore. Dismenore adalah nyeri pada daerah panggul 
akibat menstruasi dan produksi zat prostaglandin. Sringkali dimulai segera setelah mengalami menstruasi pertama (menarche). Penyebab nyeri berasal dari otot rahim, seperti semua otot lainnya otot rahim dapat berkontraksi dan relaksasi. Saat mentruasi kontraksi lebih kuat, kontraksi yang terjadi adalah akibat suatu zat yang namanya prostaglandin..(Proverawati A,2015)

Dismenore dibedakan menjadi dua yaitu dismenore primer dan dismenore sekunder. Dismenore primer disebabkan tingginya kadar prostaglandin, hal ini tidak berbahaya. Dismenore sekunder disebabkan oleh tumor fibroid, penyakit radang panggul, adanya kista pada indung telur.( Haryono R., 2016)

Menurut Word Health Organization (WHO) angka dismenoe di dunia sangat besar rata-rata lebih dari $50 \%$ perempuan di setiap Negara mengalami dismenore. Di Amerika Serikat diperkirakan hampir 90\% wanita mengalami dismenore dan 10-15\% mengalami dismenore berat, yang menyebabkan mereka tidak mampu melakukan kegiatan apapun dan ini akan menurunkan kualitas hidup. Bahkan di Amerika diperkirakan perempuan kehilangan 1,7 juta hari kerja setiap bulan akibat dismenore. Dismenore menyebabkan $14 \%$ dari pasien remaja sering tidak hadir di sekolah dan tidak menjalani kegiatan sehari-hari.( Wariyah, Sugiri H, Makhrus I, 2019)

Menurut Survei Demografi Kesehatan Indonesia (SDKI), di Indonesia remaja putri mendiskusikan tentang haid dengan teman sebesar 58\%, diskusi bersama ibunya sebesar $45 \%$. Satu dari lima remaja tidak mendiskusikan tentang haid dengan orang lain sebelum mengalami haid yang pertama. Remaja putri yang mengalami nyeri haid saat menstruasi sebesar $76 \%$, remaja putri yang tidak mengalami nyeri haid saat menstruasi sebesar 58\%.(SDKI, 2017)

Berdasarkan data Sumatera Utara dari penelitian tentang dismenore di Kota Medan seperti dilakukan Sirait (2014) bahwa proporsi prevalens dismenore pada remaja putri di SMA Negeri 2 Medan tahun 2014 adalah $(85,9 \%)$. Dengan proporsi tertinggi pada kelompok umur 14-15 tahun $(86,0 \%)$, umur menarche $<12$ tahun $(87,7 \%)$, lama menstruasi $<7$ hari $(86,3 \%)$, siklus menstruasi normal $(87,4 \%)$, sering berolahraga $(96,9 \%)$, status gizi lebih (100\%), dan ada riwayat keluarga (90,5\%).( Sirait D shinta, Hiswani, Jemadi, 2014)

Faktor-faktor yang berhubungan dengan dismenore pada remaja putri yaitu usia menarche, lama menstruasi, dan riwayat keluarga. Menarche merupakan menstruasi pertama yang biasa terjadi dalam rentang usia 10-16 tahun. Menarche pada usia lebih awal menyebabkan alat-alat reproduksi belum siap mengalami perubahan-perubahan sehingga timbul nyeri ketika menstruasi.( Kasumayanti E, 2015)

Lama menstruasi normal adalah 4-7 hari dengan jumlah darah 30-80 ml, bila menstruasi terjadi lebih lama mengakibatkan uterus lebih sering berkontraksi dan semakin banyak prostaglandin yang dikeluarkan.
Produksi prostaglandin yang berlebihan menimbulkan rasa nyeri, sedangkan kontraksi uterus yang terus menerus menyebabkan suplay darah ke uterus terhenti dan terjadi dismenore.( Kasumayanti E, 2015)

Dalam sebuah unit keluarga, disfungsi apa saja (penyakit, cedera, perpisahan) akan memengaruhi satu atau lebih anggota keluarga dalam hal tertentu. Keluarga merupakan jaringan yang mempunyai hubungan erat serta bersifat mandiri, dan masalah seorang individu dapat memngaruhi anggota keluarga yang lain serta seluruh sistem.( Ali HZ, 2010)

Berdasarkan hasil penelitian dari Angelina, dkk dengan judul faktor-faktor yang berhubungan dengan kejadian dismenore pada remaja putri di SMA Kecamatan Sengah Temila Kabupaten Landak bahwasanya usia menarche $(\mathrm{P}$ Value $=0,024)$, paparan asap rokok $(\mathrm{P}$ Value $=0,003)$, siklus mentstruasi $(\mathrm{P}$ Value $=0,019$ ), maka terdapat hasil ada hubungan antara usia menarche, paparan asap rokok, siklus menstruasi dengan kejadian dismenore. Dan status gizi ( $\mathrm{P}$ Value $=$ 1,000), lama menstruasi ( $\mathrm{P}$ Value $=0,552)$, riwayat keluarga $(\mathrm{P}$ Value $=0.076)$, stress $(\mathrm{P}$ Value $=0,594)$, maka terdapat hasil tidak ada hubungan antara status gizi, lama menstruasi, riwayat keluarga dengan kejadian dismenore. ( Angelina, Ridha A, Alamsyah D, 2017)

Berdasarkan hasil survei awal yang telah dilakukan kepada seluruh remaja putri di MTs Negeri 3 Medan, peneliti melakukan wawancara terhadap 22 remaja putri. Terdapat 16 remaja putri mengalami dismenore, dan 6 remaja putri lainnya tidak mengalami dismenore. Dari 6 remaja yang tidak mengalami dismenore, terdapat 6 remaja dengan kelompok usia menarche $>12$ tahun, lama menstruasi $<7$ hari, dan tidak ada riwayat dismenore pada keluarga. Dari 16 remaja yang mengalami dismenore terdapat 5 remaja dengan usia menarche <12 tahun, 11 remaja dengan usia menarche $>12$ tahun. 14 remaja dengan lama menstruasi $<7$ hari dan 2 remaja dengan lama menstruasi $>7$ hari. 11 remaja ada riwayat dismenore pada keluarga dan 5 remaja tidak ada riwayat dismenore pada keluar.

Tujuan Penelitian ini adalah untuk mengetahui Faktor Yang Berhubungan Dengan Dismenore pada remaja putri di MTs Negeri 3 Medan Tahun 2019.

\section{METODE}

Jenis penelitian ini adalah penelitian survey analitik (survei atau penelitian yang mencoba menggali bagaimana dan mengapa fenomena kesehatan itu terjadi) dengan menggunakan pendekatan cross sectional yang bertujuan untuk melakukan pengukuran atau pengamatan pada saat bersamaan (sekali waktu) risiko atau paparan dengan penyakit dengan Faktor yang Berhubungan dengan Dismenore di MTs Negeri 3 Medan Tahun 2019.

Penelitian ini dilakukan di MTs Negeri 3 Medan yang berada di Jalan Melati XIII, Helvetia Tengah, Medan Helvetia, Kota Medan, Sumatera Utara 20124. 
Waktu yang diperlukan untuk penelitian ini adalah 3 bulan mulai dari bulan April sampai dengan Juni 2019.

\section{HASIL DAN PEMBAHASAN Analisa Univariat}

Tabel 1. Distribusi Frekuensi Dengan Dismenore Berdasarkan Usia Menarche, Lama Menstruasi, Riwayat Keluarga di MTs Negeri 3 Medan Tahun 2019

\begin{tabular}{lcc}
\hline \multicolumn{1}{c}{ Variabel } & \multicolumn{2}{c}{ Jumlah } \\
& F & \% \\
\hline Usia Menarche & & \\
$>$ 12 tahun & 17 & 29,8 \\
<12 tahun & 40 & 70,2 \\
Lama Menstruasi & & \\
$<7$ hari & 27 & 47,4 \\
$>$ 7 hari & 30 & 52,6 \\
Riwayat Keluarga & & \\
Ya & 45 & 78,9 \\
Tidak & 12 & 21,1 \\
Dismenorhea & & \\
Ya & 42 & 73,7 \\
Tidak & 15 & 26,3 \\
\hline
\end{tabular}

Berdasarkan tabel 1 dapat di ketahui bahwa dari 57 remaja putri di MTs Negeri 3 Medan Tahun 2019, terdapat usia menarche $>12$ tahun sebanyak 17 orang $(29,8 \%)$, dan usia menarche $<12$ tahun sebanyak 40 orang $(70,2 \%)$. Lama menstruasi $<7$ hari sebanyak 27 orang $(47,4 \%)$, dan lama menstruasi $>7$ hari sebanyak 30 orang $(52,6 \%)$. Memiliki riwayat keluarga sebanyak 45 orang $(78,9 \%)$ dan yang tidak memiliki riwayat keluarga sebanyak 12 orang $(21,1 \%)$. Dismenore sebanyak 42 orang $(73,7 \%)$ dan yang tidak mengalami dismenore sebanyak 15 orang $(26,3 \%)$.

\section{Analisa Bivariat}

Analisis bivariat dilakukan untuk mengetahui hubungan antara variable bebas (usia menarche, lama menstruasi dan riwayat keluarga) dan variable terikat yaitu dismenore. Untuk membuktikan adanya faktor-faktor yang berhubungan dengan dismenore pada remaja putri di MTs Negeri 3 Medan tahun 2019 yang signifikan antara variable bebas dengan variable terikat analisis Chi-square, pada batas kemaknaan perhitungan statistic $\mathrm{p}$ Value $(0,05)$. Apabila hasil perhitungan menunjukkan nilai $\mathrm{p}<\mathrm{p}$ Value $(0,05)$ maka dikatakan (Ho) ditolak < artinya kedua variabel secara statistik mempunyai hubungan yang signifikan. Adanya hubungan antara variabel terikat dengan variabel bebas digunakan analisis tabulasi silang. ( Muhammad I, 2015)

Berdasarkan table 2 dapat di ketahui bahwa dari 57 remaja putri di MTs Negeri 3 Medan Tahun 2019, pada kelompok usia menarche normal yang mengalami dismenore sebanyak 9 orang $(15,8 \%)$, dan yang tidak mengalami dismenore sebanyak 8 orang $(14,0 \%)$. Pada kelompok usia menarche tidak normal yang mengalami dismenore sebanyak 33 orang $(57,9 \%)$, dan yang tidak mengalami dismenore sebanyak 7 orang (12,3\%). Lama menstruasi normal yang mengalami dismenore sebanyak 16 orang $(28,1 \%)$, dan yang tidak mengalami dismenore sebanyak 11 orang $(19,3 \%)$. Sedangkan dengan lama menstruasi tidak normal yang mengalami dismenore sebanyak 26 orang $(45,6 \%)$, dan yang tidak mengalami dismeore sebanyak 4 orang $(7,0 \%)$. Riwayat keluarga mengalami dismenore sebanyak 37 orang $(64,9 \%)$ dan yang tidak mengalami dismenore sebanyak 8 orang $(14,0 \%)$. Sedangkan yang tidak memiliki riwayat keluarga mengalami dismenore sebanyak 5 orang $(8,8 \%)$, dan yang tidak mengalami dismeore sebanyak 7 orang $(12,3 \%)$.

Tabel 2. Tabulasi silang antara Hubungan Usia Menarche, Lama Menstruasi dan Riwayat Keluarga Dengan Dismenore di MTs Negeri 3 Medan Tahun 2019

\begin{tabular}{|c|c|c|c|c|c|c|c|}
\hline \multirow{3}{*}{ Variabel } & \multicolumn{4}{|c|}{ Dismenore } & \multirow{2}{*}{\multicolumn{2}{|c|}{ Jumlah }} & \multirow{3}{*}{$\boldsymbol{P}$} \\
\hline & \multicolumn{2}{|c|}{ Ya } & \multicolumn{2}{|c|}{ Tidak } & & & \\
\hline & $\mathbf{F}$ & $\%$ & $\mathbf{f}$ & $\%$ & $\mathbf{F}$ & $\%$ & \\
\hline Usia Menarche & & & & & & & \\
\hline Normal & 9 & 15,8 & 8 & 14,0 & 17 & 29,8 & \\
\hline Tidak Normal & 33 & 57,9 & 7 & 12,3 & 40 & 70,2 & 0,045 \\
\hline Lama Menstruasi & & & & & & & \\
\hline Normal & 16 & 28,1 & 11 & 19,3 & 27 & 47,4 & \\
\hline Tidak Normal & 26 & 45,6 & 4 & 7,0 & 30 & 52,6 & 0,033 \\
\hline Riwayat Keluarga & & & & & & & \\
\hline Ya & 37 & 64,9 & 8 & 14,0 & 45 & 78,9 & 0009 \\
\hline Tidak & 5 & 8,8 & 7 & 12,3 & 12 & 21,1 & \\
\hline
\end{tabular}

\section{Pembahasan}

Hubungan Usia Menarche dengan Dismenore di MTs Negeri 3 Medan Tahun 2019

Berdasarkan hasil penelitian dapat diketahui bahwa dari 57 remaja putri di MTs Negeri 3 Medan Tahun 2019, pada kelompok usia menarche normal yang mengalami dismenore sebanyak 9 orang $(15,8 \%)$, dan yang tidak mengalami dismenore sebanyak 8 orang
(14,0\%). Pada kelompok usia menarche tidak normal yang mengalami dismenore sebanyak 33 orang (57,9\%), dan yang tidak mengalami dismenore sebanyak 7 orang $(12,3 \%)$. Hasil chi-square diperoleh nilai $p=0,045$. Dengan demikian dapat ditarik kesimpulan bahwa terdapat hubungan usia menarche dengan dismenore di MTs Negeri 3 Medan Tahun 2019. 
Hasil penelitian ini juga sejalan dengan penelitian yang dilakukan oleh Eka Ramadhayanti dkk dengan judul Hubungan Status Gizi dan Usia Menarche Dengan Dismenore Primer Pada Remaja Putri Kelas XI SMA Negeri 15 Palembang, berdasarkan hasil penelitian dapat diketahui bahwa dari 75 remaja putri yang memiliki status gizi tidak normal mengalami dismenore primer sebanyak 38 orang $(90,5 \%)$ dan yang tidak mengalami dismenore primer sebanyak 4 orang $(9,5 \%)$, sedangkan yang memiliki status gizi normal mengalami dismenore primer sebanyak 23 orang $(69,7 \%)$ dan yang tidak mengalami dismenore primer sebanyak 10 orang $(30,3 \%)$. Pada siswi dengan usia menarche tidak normal yang mengalami dismenore sebanyak 41 orang $(91,1 \%)$ dan yang tidak mengalami dismenore sebanyak 4 orang $(8,9 \%)$, sedangkan dengan menarche normal yang mengalami dismenore sebanyak 20 orang $(66,7 \%)$ dan yang tidak mengalami dismenore sebanyak 10 orang $(33,3 \%)$. Hasil uji statistik diperoleh bahwa ada hubungan antara status gizi dengan kejadian dismenore primer dengan nilai $\mathrm{p}=0,046$ dan usia menarche dengan kejadian dismenore primer dengan nilai $\mathrm{p}=0,018$.

Menarche merupakan menstruasi pertama yang biasa terjadi dalam rentang usia 10-16 tahun atau pada masa awal remaja ditengah masa pubertas sebelum memasuki masa reproduksi. Menarche merupakan suatu tanda awal adanya perubahan lain seperti pertumbuhan payudara, pertumbuhan rambut daerah pubis dan aksila, sertadi stribusi lemak pada daerah pinggul. Menarche pada usia lebih awal menyebabkan alat-alat reproduksi belum siap mengalami perubahan-perubahan sehingga timbul nyeri ketika menstruasi.

Perempuan yang mengalami menstruasi dini disebabkan oleh faktor internal dan eksternal. Faktor internal karena ketidak seimbangan hormone bawaan lahir. Hal ini juga berkorelasi dengan faktor eksternal seperti asupan gizi pada makanan yang dikonsumsi. Tingkat kualitas gizi yang lebih baik pada masyarakat saat ini memicu menstruasi dini. Tapi, gizi yang kurang juga mengakibatkan hal yang sama.

Menurut asumsi peneliti, ada beberapa remaja putri pada kelompok usia menarche normal tetapi mengalami dismenore dikarenakan pola hidup yang tidak sehat seperti sering makan junk food, merokok, tidak pernah berolahraga, dll yang dapat memicu peningkatan rasa nyeri pada saat menstruasi. Sedangkan pada beberapa remaja putri pada kelompok usia menarche tidak normal yang mengalami dismenore dikarenakan usia menarche yang terlau dini menyebabkan alat-alat reproduksi belum siap mengalami perubahan-perubahan sehingga timbul nyeri ketika menstruasi.

Dan kelompok usia menarche normal yang tidak mengalami dismenore dikarenakan usia menarche $>12$ tahun merupakan usia menarche normal dalam mengalami perubahan reproduksi sehingga tidak timbul nyeri ketika menstruasi. Sedangkan pada kelompok usia menarche tidak normal tetapi tidak mengalami dismenore dikarenakan mereka memiliki pola hidup sehat yang dapat mengurangi rasa sakit pada saat menstruasi.

\section{Hubungan Lama Menstruasi dengan Dismenore di MTs Negeri 3 Medan Tahun 2019}

Berdasarkan hasil penelitian dapat diketahui bahwa dari 57 remaja putri di MTs Negeri 3 Medan Tahun 2019, dengan lama menstruasi normal yang mengalami dismenore sebanyak 16 orang $(28,1 \%)$, dan yang tidak mengalami dismenore sebanyak 11 orang $(19,3 \%)$. Sedangkan lama menstruasi tidak normal yang mengalami dismenore sebanyak 26 orang $(45,6 \%)$, dan yang tidak mengalami dismeore sebanyak 4 orang $(7,0 \%)$. Hasil chi-square diperoleh nilai $p=0,033$. Dengan demikian dapat ditarik kesimpulan bahwa terdapat hubungan lama menstruasi dengan dismenore di MTs Negeri 3 Medan Tahun 2019.

Penelitian ini sejalan dengan penelitian yang dilakukan oleh Tia Martha Pundati dengan judul Faktorfaktor yang berhubungan dengan kejadian dismenore pada mahasiswa semester VIII Universitas Jenderal Soedirman Purwokerto Tahun 2016, berdasarkan hasil penelitian dapat diketahui bahwa $67,1 \%$ responden mengalami dismenore, $57,6 \%$ responden berusia di atas 12 tahun, $71,8 \%$ responden tidak memiliki riwayat keuarga, $55,3 \%$ memiliki riwayat $>7$ hari, 50,6\% mengalami stress, dan $51,7 \%$ memiliki aktivitas fisik rutin. Berdasarkan hasil uji chi-square menunjukkan bahwa ada hubungan yang signifikan antara lama menstruasi dengan kejadian dismenore dengan nilai $\mathrm{p}=$ 0,005 , stress dengan kejadian dismenore dengannilai $\mathrm{p}=$ 0,045. Dan tidak ada hubungan antara usia menarche, riwayat keluarga dan kebiasaan olahraga dengan kejadian dismenore.

Lama haid biasanya antara 4 sampai 7 hari, ada yang 1 sampai 2 hari dan diikuti darah sedikit-sedikit kemudian, dan ada yang sampai 7 sampai 8 hari. Pada setiap wanita biasanya lama haid itu tetap. Kurang lebih $50 \%$ darah menstruasi dikeluarkan dalam 24 jam pertama. Cairan menstruasi terdiri dari auto lysis fungsional, exudat inflamasi, sel darah merah, dan enzympretolitik.

Lama menstruasi normal adalah 4-7 hari dengan jumlah darah 30-80 ml, bila menstruasi terjadi lebih lama mengakibatkan uterus lebih sering berkontraksi dan semakin banyak prostaglandin yang dikeluarkan. Produksi prostaglandin yang berlebihan menimbulkan rasa nyeri, sedangkan kontraksi uterus yang terus menerus menyebabkan suplay darah ke uterus terhenti dan terjadi dismenore.

Menurut asumsi peneliti, beberapa remaja putri yang memiliki lama menstruasi normal tetapi mengalami dismenore dikarenakan pola hidup yang tidak sehat seperti sering makan junk food, merokok, tidak pernah berolahraga, dll yang dapat memicu peningkatan rasa 
nyeri pada saat menstruasi. Sedangkan yang memiliki lama menstruasi tidak normal dan megalami dismenore dikarenakan bila menstruasi terjadi lebih lama mengakibatkan uterus lebih sering berkontraksi dan semakin banyak prostaglandin yang dikeluarkan, produksi prostaglandin yang berlebihan menimbulkan rasa nyeri sedangkan kontraksi uterus yang terus menerus menyebabkan suplay darah ke uterus terhenti dan terjadi dismenore.

Dan remaja putri yang memiliki lama menstruasi normal tidak mengalami dismenore dikarenakan lama menstruasi $<7$ hari tidak mengakibatkan uterus sering berkontraksi sehingga tidak terjadi nyeri saat menstruasi. Sedangkan yang memiliki lama menstruasi tidak normal tetapi tidak mengalami dismenore dikarenakan mereka memiliki pola hidup sehat yang dapat mengurangi rasa sakit pada saat menstruasi.

\section{Hubungan Riwayat Keluarga dengan Dismeore di MTs Negeri 3 Medan Tahun 2019}

Berdasarkan hasil penelitian dapat diketahui bahwa dari 57 remaja putri di MTs Negeri 3 Medan Tahun 2019, yang memiliki riwayat keluarga mengalami dismenore sebanyak 37 orang $(64,9 \%)$ dan yang tidak mengalami dismenore sebanyak 8 orang $(14,0 \%)$. Sedangkan yang tidak memiliki riwayat keluarga mengalami dismenore sebanyak 5 orang $(8,8 \%)$, dan yang tidak mengalami dismeore sebanyak 7 orang $(12,3 \%)$. Hasil chi-square diperoleh nilai $p=0,009$. Dengan demikian dapat ditarik kesimpulan bahwa terdapat hubungan riwayat keluarga dengan dismenore di MTs Negeri 3 Medan Tahun 2019.

Penelitian ini sejalan dengan penelitian yang dilakukan oleh Wariyah dengan judul Faktor-faktor yang berhubungan dengan kejadian dismenore pada siswi SMP Negeri 3 Karawang Tahun 2018, berdasarkan hasil penelitian dapat diketahui bahwa pada siswi yang usai menarche $<9$ tahun mengalami dismenore tidak ada dan yang tidak mengalami dismenore sebanyak 1 orang $(100 \%)$, sedangkan yang usia menarche $>9$ tahun mengalami dismenore sebanyak 46 orang $(56,1 \%)$ dan tidak mengalami dismenore sebanyak 36 orang $(43,9 \%)$. Pada siswi yang lama menstruasi $<7$ hari mengalami dismenore sebanyak 20 orang $(57,1 \%)$ dan tidak mengalami dismenore sebanyak 15 orang $(42,9 \%)$, sedangkan yang lama menstruasi $>7$ hari mengalami dismenore sebanyak 26 orang $(54,2 \%)$ dan tidak mengalami dismenore sebanyak 22 orang $(45,8 \%)$. Pada siswi yang memiliki riwayat keluarga mengalami dismenore sebanyak 40 orang $(78,4 \%)$ dan tidak mengalami dismenore sebanyak 11 orang $(21,6 \%)$, sedangkan yang tidak memiliki riwayat keluarga mengalami dismenore sebanyak 6 orang dan tidak mengalami dismenore sebanyak 26 orang $(81,2 \%)$. Pada siswi yang berolahraga mengalami dismenore sebanyak 4 orang $(20,0 \%)$ dan tidak mengalami dismenore sebanyak 16 orang $(80,0 \%)$, sedangkan yang tidak berolahraga mengalami dismenore sebanyak 42 orang $(66,7 \%)$ dan tidak mengalami dismenore sebanyak 21 orang $(33,3 \%)$. Hasil uji chi-square menunjukkan adanya hubungan yang bermakna antara riwayat keluarga dengan kejadian dismenore dengan nilai $\mathrm{p}=$ 0,00 , olahraga dengan kejadian dismenore dengan nilai $\mathrm{p}$ $=0,00$. Dan tidak ada hubungan antara usia menarche dan lama menstruasi dengan kejadian dismenore.

Dalam sebuah unit keluarga, disfungsi apa saja (penyakit, cedera, perpisahan) akan memengaruhi satu atau lebih anggota keluarga dalam hal tertentu. Keluarga merupakan jaringan yang mempunyai hubungan erat serta bersifat mandiri, dan masalah seorang individu dapat memngaruhi anggota keluarga yang lain serta seluruh sistem. Jika seorang perawat hanya mengkaji seorang individu saja bukan keluarga, ia akan kehilangan bagian lain yang dibutuhkan untuk memperoleh pengkajian holistik.

Menurut asumsi peneliti, ada beberapa remaja putri yang memiliki riwayat keluaraga dan mengalami dismenore dikarenakan riwayat kesehatan keluarga sangat berpengaruh terhadap kondisi kesehatan anggota keluarga itu sendiri dan merupakan faktor resiko yang sangat mendukung terjadi suatu penyakit yang sama di lingkungan keluarga. Sedangkan yang tidak memiliki riwayat keluarga tetapi mengalami dismenore dikarenakan pola hidup yang tidak sehat seperti sering makan junk food, merokok, tidak pernah berolahraga, dll yang dapat memicu peningkatan rasa nyeri pada saat menstruasi.

Dan pada remaja putri yang memiliki riwayat keluarga tetapi tidak mengalami dismenore dikarenakan mereka memiliki pola hidup sehat yang dapat mengurangi rasa sakit pada saat menstruasi. Sedangkan yang tidak memiliki riwayat keluarga dan tidak mengalami dismenore dikarenakan tidak ada riwayat kesehatan keluarga yang dapat mempengaruhi terjadinya nyeri pada saat menstruasi.

\section{SIMPULAN}

Terdapat hubungan yang bermakna antara usia menarche dengan dismenore pada remaja putri dengan $\rho$-value $0,045<0,05$. Terdapat hubungan yang bermakna antara lama menstruasi dengan dismenore pada remaja putri dengan $\rho$-value $0,033<0,05$. Terdapat hubungan yang bermakna antara riwayat keluarga dengan dismenore pada remaja putri dengan $\rho$-value $0,009<0,05$.

\section{DAFTAR PUSTAKA}

Ali HZ. Pengantar Keperawatan Keluarga. Jakarta: Penerbit Buku Kedokteran EGC; 2010.

Apriyanti F, Harmia E, Andriani R. Hubungan Status Gizi dan Usia Menarche Dengan Kejadian Dismenore Pada Remaja Putri di SMAN 1 Bangkinang Kota Tahun 2018. 2018;41(4):34562. 
Febriati LD. Faktor-Faktor Yang Berhubungan Dengan Kejadian Dismenorea pada Mahasiswi Prodi D III Kebidanan Fakultas Ilmu Kesehatan Universitas Respati Yogyakarta Tahun 2015. J Med Respati ISSN 1907 - 3887. 2016;XI(2):12-22.

Haryono R. Siap Menghadapi Menstruasi \& Menopause. Yogyakarta: Gosyen Publishing; 2016.

Herawati R. Faktor Yang Mempengaruhi Kejadian Nyeri Haid (Dismenorea) Pada Siswi Madrasah Aliyah Negeri Pasir Pangaraian. 2017;

Kasumayanti E. Faktor-Faktor Yang Berhubungan Dengan Kejadian Disminore Di Sman 5 Pekanbaru. STIKes Tuanku Tambusai. 2015;(4):20-8.

Lestari TW, Ulfiana E, Suparmi. Buku Ajar Kesehatan Reproduksi. Jakarta: Penerbit Buku Kedokteran EGC; 2014.

Muhammad I. Panduan Penyusunan Karya Tulis Ilmiah Bidang Kesehatan Menggunakan Metode Ilmiah. Medan: Citrapustaka Media Perintis; 2015.

Ningsih NS. Faktor-Faktor Yang Berhubungan Dengan Dismenore Pada Siswi SMA Santika Jakarta. 2015;10(2):106-19.

Proverawati A, Maisaroh S. MENARCHE Menstruasi Pertama Penuh Makna. Yogyakarta: Nuha Medika; 2015.

Pundati TM, Sistiarani C, Hariyadi B. Faktor-Faktor Yang Berhubungan Dengan Kejadian Dismenore Pada Mahasiswa Semester VIII Universitas Jenderal Soedirman Purwekerto. 2016;

Sari AP, Siregar FA, Rasmaliah. Faktor-Faktor Yang Berhubungan Dengan Kejadian Dismenorea Pada Siswi SMK Swasta Istiqlal Kabupaten Deli Serdang. 2017;30(11):191-5.

Sibagariang EE. Kesehatan Reproduksi Wanita Edisi Revisi. Jakarta Timur: CV. Trans Info Media; 2016.

Sinaga E, Saribanon N, Sa'adah SN, Salamah U, Murti YA, Trisnamiati A, et al. Manajemen Kesehatan Menstruasi. Global One; 2017.

Sirait D shinta, Hiswani, Jemadi. Faktor-Faktor yang Berhubungan dengan Kejadian Dismenore Pada Siswi SMA Negeri 2 Medan Tahun 2014. J USU [Internet]. 2014;1. Available from: http://jurnal.usu.ac.id/index.php/gkre/article/view/ 8583

Survei Demografi dan Kesehatan Indonesia 2017: Kesehatan Reproduksi Remaja. 2017;

Wariyah, Sugiri H, Makhrus I. Faktor-Faktor Yang Berhubungan Dengan Dismenorea Pada Siswi SMP Negeri 3 Karawang Barat Kabupaten Karawang Tahun 2018. 2019;10(1):39-48.

Wiknjosastro PDH, Prawirohardjo PDDS. Ilmu Kandungan Edisi Ketiga. Jakarta: PT Bina Pustaka Prawirohardjo; 2017. 